\title{
Review
}

\section{The direct and indirect effects of insulin on hepatic glucose production in vivo}

\author{
A.D. Cherrington, D. Edgerton, D. K. Sindelar \\ Department of Molecular Physiology and Biophysics, Vanderbilt University School of Medicine, Nashville, USA
}

\section{Introduction}

Glucose production by the liver is controlled on a minute to minute basis by the plasma insulin and glucagon concentrations. Glucagon increases glycogen breakdown and stimulates the gluconeogenic pathway and insulin inhibits both glycogenolysis and gluconeogenesis [1]. Until ten years ago it was generally accepted that the insulin level within the hepatic sinusoids was responsible for the hormone's inhibitory effect on the liver. Recently, however, that concept has been challenged.

In 1987 this concept was first called into question [2]. It was noted that in obese non-diabetic humans suppression of glucose production could occur in response to insulin infusion even when the estimated portal insulin concentrations did not rise. Insulin was infused into a peripheral vein and euglycaemia was maintained with a glucose infusion. Endogenous insulin secretion, estimated from C-peptide concentrations, decreased by about $50 \%$ over the course of the experiment. Based on the fall in endogenous insulin release and the prevailing peripheral insulin concentration, the authors estimated that the portal vein insulin concentration probably remained unchanged. Nevertheless glucose production was suppressed by about $80 \%$ at the end of their study. It should be remembered, however, that about $20 \%$ of liver blood flow is derived from the hepatic artery, so a rise in arterial insulin would have increased the liver sinusoidal insulin concentration somewhat, even though the portal insulin level did not change. Likewise, although the authors assumed that their tracer data

Corresponding author: A.D. Cherrington, $\mathrm{PhDepartment} \mathrm{of}$ Molecular Physiology and Biophysics, Vanderbilt University School of Medicine, Nashville, TN 37232-0615, USA Abbreviations: G6P, Glucose-6-phosphate; NEFA, non-esterified fatty acid; NHGO, net hepatic glucose output. yielded an estimate of hepatic glucose production, it is now clear that it reflects both hepatic and renal glucose output [3]. After an overnight fast renal glucose production is not great $(5-25 \%$ of total glucose production) but it is insulin sensitive [4]. It is likely therefore that a small portion of the insulin induced fall in glucose production which they observed was due to a decrease in renal glucose production. Despite the above caveats, the study [2] was of importance because it was the first to focus attention on the indirect effect of insulin to inhibit glucose production by the liver.

To further investigate the effect of peripherally delivered insulin on glucose production, experiments were carried out [5] in which conscious dogs were given insulin intraportally (at 0.3 to $10 \mathrm{pmol} \cdot \mathrm{kg}^{-1}$. $\mathrm{min}^{-1}$ ) or peripherally at half the portal rate. Since the liver clears approximately half of the insulin which reaches it, the systemic insulin concentrations were the same in the two protocols but those of portal insulin differed. Euglycaemia was maintained by glucose infusion. To eliminate insulin-induced changes in plasma glucagon, somatostatin was infused and glucagon was replaced, but at a rate fivefold to tenfold basal. The authors found that insulin reduced tracer-determined glucose production in a parallel dose-dependent manner in both groups despite the presence of higher portal insulin concentrations in one group. In agreement with this, it was shown [6] that infusion of insulin into depancreatized dogs intraportally at $5.4 \mathrm{pmol} \cdot \mathrm{kg}^{-1} \cdot \mathrm{min}^{-1}$ or peripherally at $2.7 \mathrm{pmol} \cdot \mathrm{kg}^{-1} \cdot \mathrm{min}^{-1}$ caused similar reductions $(\simeq 50 \%)$ in tracer-determined glucose production. Unfortunately plasma glucagon declined $40 \mathrm{pg} / \mathrm{ml}$ in both groups, complicating data interpretation. Nevertheless, taken together both of these studies supported the concept that insulin's indirect actions on the liver were more important in decreasing glucose production than thought previously. The authors also in- 
terpreted their findings to suggest that portal vein insulin concentrations were less important than thought previously, since the presence of extra insulin in the liver sinusoids failed to cause a greater decrease in glucose production during portal insulin infusion.

Since it is not possible to infuse insulin intraportally in humans a different approach had to be used Tolbutamide was infused to increase endogenous insulin secretion and the latter was determined using changes in C-peptide concentrations [7]. Finally, in additional experiments insulin was delivered via a peripheral vein in the same subjects at a rate equivalent to the endogenous insulin secretion rate or at a rate half that value. Glucose was infused to maintain euglycaemia. A greater fall in glucose production was seen in the full rate peripheral insulin infusion group than in the endogenous insulin secretion group. Furthermore, if one compares the data from the half rate peripheral delivery group with that of the endogenous insulin secretion group, the fall in glucose production was only slightly greater in the latter group (50 vs $37 \%$ ) despite indistinguishable systemic insulin concentrations $(\simeq 170 \mathrm{pmol} / \mathrm{l})$ and $\mathrm{a}$ much higher liver sinusoidal insulin concentration (443 vs $205 \mathrm{pmol} / \mathrm{l})$. Thus the extra $238 \mathrm{pmol} / \mathrm{l}$ of sinusoidal insulin only caused glucose production to decline an additional $13 \%$. Glucagon fell by approximately $15 \mathrm{pg} / \mathrm{ml}$ in both groups and, although this fall may have contributed to the overall suppression of glucose production, it cannot explain the difference observed in the two groups. This study, therefore, once again suggested the importance of insulin's indirect inhibitory effect on liver glucose output.

\section{Effects of a selective rise in the arterial insulin concentration}

In all of the above studies, whether insulin was given via a peripheral vein or the portal vein, both the systemic and liver sinusoidal insulin concentrations rose concurrently. This complicates data interpretation, since without knowing the dose response relation between a selective rise in plasma insulin at each site and the response of the liver, it is difficult to draw clear conclusions. Our first aim, therefore, was to directly assess the effect of a selective rise in systemic insulin (i.e. brought about in the absence of a change in portal insulin) on glucose production in the conscious overnight fasted dog [8]. In order to eliminate glucagon as a variable we clamped the hormone at its basal value $(\simeq 40 \mathrm{pg} / \mathrm{ml})$ using the pancreatic clamp technique. Furthermore, we measured glucose production using A-V difference and tracer techniques simultaneously. In this way we were able to measure net hepatic glucose output directly so that we could specifically draw conclusions about hepatic (as opposed to hepatic and renal) glucose production.
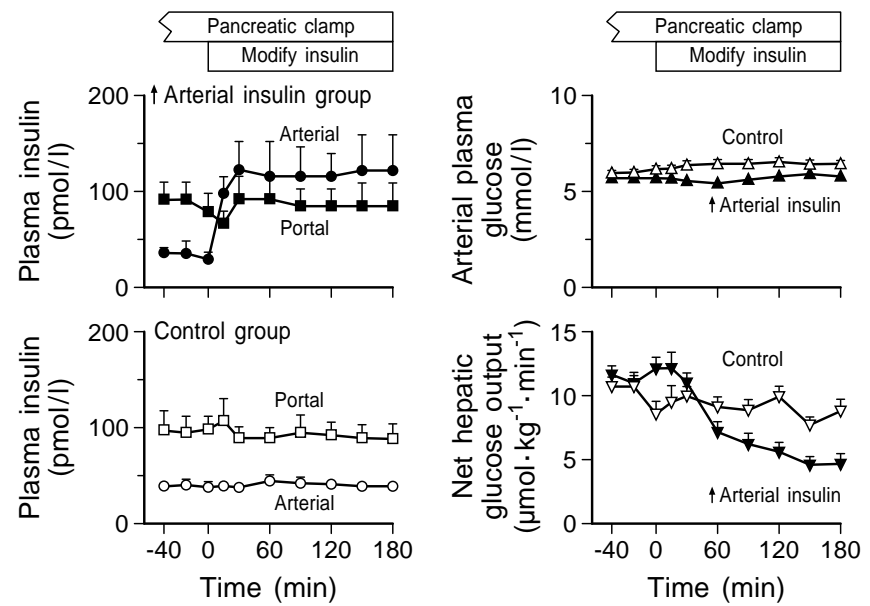

Fig. 1. The effect of a selective rise in arterial insulin on net hepatic glucose output in the conscious overnight fasted dog. Euglycaemia was maintained by glucose infusion and glucagon was kept basal. The data are redrawn from reference 8

The design of the study was such that we first carried out a pancreatic clamp (somatostatin infusion plus basal portal insulin and glucagon replacement) to take over control of the animal's endocrine pancreas. After a $40 \mathrm{~min}$ control period the portal vein insulin infusion was stopped and insulin was given into a leg vein at twice the portal vein infusion rate. As can be seen in Figure 1 this increased arterial plasma insulin from 36 to $120 \mathrm{pmol} / \mathrm{l}$. The measured portal insulin concentration did not change ( $84 \mathrm{vs} 84 \mathrm{pmol} / \mathrm{l}$ ), but as a result of the increase in arterial insulin plasma insulin within the liver sinusoids rose slightly (71 to 94 $\mathrm{pmol} / \mathrm{l})$. The plasma glucagon concentration remained unchanged (data not shown) and euglycaemia (Fig. 1) was maintained by glucose infusion. A control group was treated identically except that no change was made in the basal rate of portal insulin infusion. Thereby it was shown (Fig. 1) that in response to the selective rise in arterial insulin, net hepatic glucose output changed minimally in the first $30 \mathrm{~min}$. It then fell until it was reduced, relative to the rate in the control group, by approximately $5 \mu \mathrm{mol} \cdot \mathrm{kg}^{-1}$. $\mathrm{min}^{-1}$. A similar fall occurred in tracer-determined glucose production (data not shown). Clearly a small change in the arterial plasma insulin ( $84 \mathrm{pmol} / \mathrm{l})$ was able to decrease glucose output by the liver in the complete absence of a rise in portal insulin. This study thus confirmed the conclusion of the earlier studies $[2,5,6]$. Further, it indicated that it was indeed an hepatic (not renal) effect of insulin which was primarily responsible for the decrease in glucose production, and that this reduction could occur in the absence of a change in plasma glucagon.

Our data not only allowed us to confirm the ability of arterial insulin to inhibit hepatic glucose release, but also allowed us to shed light on the mechanism by which this effect comes about. The fall in glucose 
production caused by the rise in systemic insulin appeared to result from three actions of the hormone. First, the rise in arterial insulin caused a slight reduction in the availability of gluconeogenic precursors to the liver, and as a result net hepatic gluconeogenic precursor uptake fell from 8 to $6 \mu \mathrm{mol} \cdot \mathrm{kg}^{-1} \cdot \mathrm{min}^{-1}$. This drop of $2 \mu \mathrm{mol} \cdot \mathrm{kg}^{-1} \cdot \mathrm{min}^{-1}$ in gluconeogenic precursor uptake could account for no more than $1 \mu \mathrm{mol} \cdot \mathrm{kg}^{-1} \cdot \mathrm{min}^{-1}$ of the decline in net hepatic glucose output. More importantly, net hepatic lactate production increased in response to the selective rise in arterial insulin. The source of this lactate was glucose-6-phosphate (G6P) which underwent glycolysis within the liver rather than being exported as glucose. This explains another $2 \mu \mathrm{mol} \cdot \mathrm{kg}^{-1} \cdot \mathrm{min}^{-1}$ of the reduction in net hepatic glucose output. The remaining $2 \mu \mathrm{mol} \cdot \mathrm{kg}^{-1} \cdot \mathrm{min}^{-1}$ were attributable to the insulinization of the hepatic sinusoids which in turn resulted from the increase in the hepatic artery insulin concentration. Since we assessed gluconeogenesis, net hepatic glucose output and net hepatic lactate balance directly, we were able to estimate the rate of glycogen breakdown. In this regard, our data showed that the glycogenolytic rate was only slightly reduced $\left(\simeq 2.0 \mu \mathrm{mol} \cdot \mathrm{kg}^{-1} \cdot \mathrm{min}^{-1}\right)$. Furthermore, as will become evident later in this review, this decline in glycogenolysis occurred because of the increase in the liver sinusoidal insulin which resulted from the contribution of arterial blood to overall sinusoidal blood flow. Most importantly the indirect effect of insulin on the liver appeared to alter the gluconeogenic rate and the fate of glucose within the hepatocyte, but not the rate of glycogenolysis.

\section{The role of non-esterified fatty acids (NEFA) in the indirect action of insulin on the liver}

The increase in net hepatic lactate production was particularly intriguing as it correlated in time almost perfectly with decline in plasma NEFA and the fall in net hepatic NEFA uptake (2.5 to $0.6 \mu \mathrm{mol} \cdot \mathrm{kg}^{-1}$. $\left.\min ^{-1}\right)$. We reasoned, therefore, that it might be the fall in lipolysis that explained the increased net hepatic lactate output. To test this hypothesis we brought about a selective rise in arterial plasma insulin in two additional groups [9]. In one we prevented the fall in the plasma NEFA and glycerol concentrations by infusing a lipid emulsion (Intralipid; Pharmacia and Upjohn, Clayton, N.C., USA) and heparin ( + NEFA; 723 vs $782 \mu \mathrm{mol} / 1$, Fig. 2) while in the other we did not infuse the lipid emulsion or heparin (-NEFA; 700 vs $310 \mu \mathrm{mol} / \mathrm{l})$. In the -NEFA group the results were as in our earlier study. Prevention of the fall in the plasma NEFA during the selective increase in arterial plasma insulin, on the other hand, reduced the fall in net hepatic glucose output (NHGO) by $3.0 \mu \mathrm{mol}$. $\mathrm{kg}^{-1} \cdot \mathrm{min}^{-1}$. A similar reduction was evident in tracer-
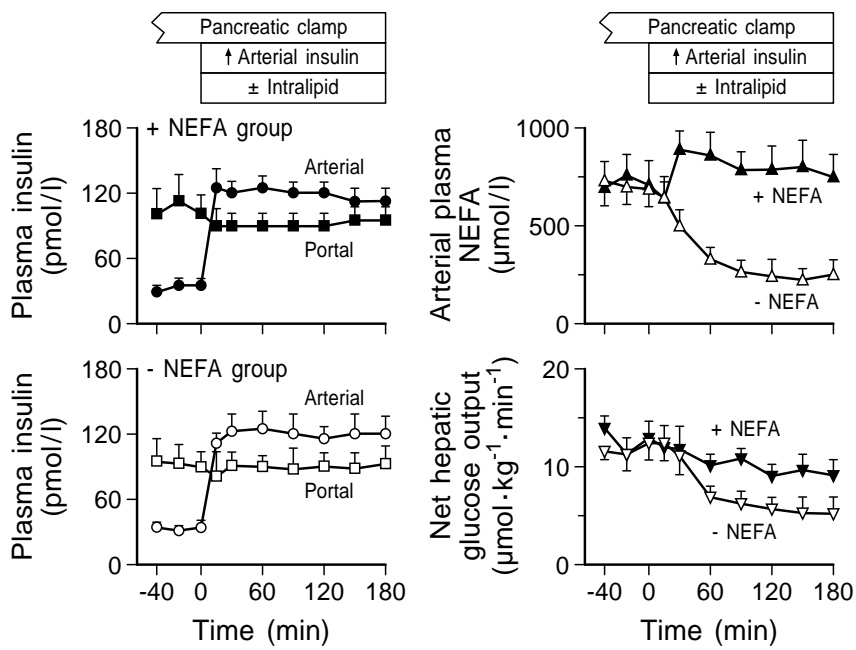

Fig. 2. The effect of the infusion of a lipid emulsion on the fall in the plasma NEFA concentration and net hepatic glucose output during a selective rise in arterial insulin in the conscious overnight fasted dog. Euglycaemia was maintained by glucose infusion and glucagon was kept basal. The data are redrawn from reference 9

determined glucose production (data not shown). The blood glycerol was mildly elevated (78 to $105 \mu \mathrm{mol}$ ) during lipid infusion and there was, as expected, a small increase in net hepatic glycerol uptake. A change in glycerol flux can thus explain approximately $1.0 \mu \mathrm{mol} \cdot \mathrm{kg}^{-1} \cdot \mathrm{min}^{-1}$ of the reduction of the fall in NHGO. The remainder $\left(2.0 \mu \mathrm{mol} \cdot \mathrm{kg}^{-1} \cdot \mathrm{min}^{-1}\right)$ was due to the increase in NEFA per se. If one corrects for the overreplacement of glycerol (i.e. $0.5 \mu \mathrm{mol}$. $\mathrm{kg}^{-1} \cdot \mathrm{min}^{-1}$ ), it is apparent that the decrease in lipolysis can explain approximately equal to $50 \%$ of the fall in net hepatic glucose output caused by the selective rise in arterial insulin. In the NEFA clamped group there was no increase in net hepatic lactate output in response to the rise in arterial insulin, indicating that it was indeed the fall in net hepatic NEFA uptake which triggered the re-direction of G6P to lactate rather than glucose. It should be noted that the results from a control study in which the plasma glycerol alone was increased indicated that it was the alteration in NEFA and not glycerol which was responsible for the increase in glycolysis. A correlation was also noted between the effects of a rise in systemic insulin on the liver and its effect on the adipocyte by others [10]. These authors also showed that the inhibitory effect of a rise in systemic insulin on the liver could be partially reduced by preventing the fall in the plasma NEFA concentration [11]. Over the last ten years a number of other studies have shown independently that NEFA concentrations can influence glucose production [12-15].

The above discussion focussed on the way in which insulin's action on fat and muscle can influence glucose production by the liver. There are two other 
ways in which a selective rise in the arterial (systemic) insulin concentration can inhibit glucose production. Although not evident from our study in which we fixed the plasma glucagon concentration, insulin acts on the $\alpha$ cell to inhibit glucagon secretion. In other studies we have examined the ability of insulin to suppress glucagon, and it appears that insulin has a dose dependent effect which begins with a rise in arterial plasma insulin of as little as $60 \mathrm{pmol} / \mathrm{l}$ [16]. This is all the more significant given the potent effect of glucagon on glucose production by the liver (i.e. a change in plasma glucagon of $10 \mathrm{pg} / \mathrm{ml}$ can alter net hepatic glucose output $0.3 \mathrm{mg} \cdot \mathrm{kg}^{-1} \cdot \mathrm{min}^{-1}$ ). Using dogs and humans respectively, it has been shown that the insulin-induced suppression of $\alpha$-cell function can explain a portion of the effect of a rise in systemic insulin on glucose production $[17,18]$.

Additionally, physiologic increments in arterial insulin concentration in conscious dogs can decrease renal glucose production [4]. This finding has been extended recently to humans [19] although a clear dose response relation between the two variables has not been established. The quantitative relevance of this action depends on the magnitude of renal glucose production. In overnight fasted humans and dogs, estimates of renal glucose production have varied from 5 to $25 \%$ of whole body glucose production, so anywhere from 1 to $5 \mu \mathrm{mol} \cdot \mathrm{kg}^{-1} \cdot \mathrm{min}^{-1}$ of glucose could be derived from the kidneys. Our data suggest that in the overnight fasted dog the renal glucose production rate is close to $10 \%$ of tracer-determined glucose production, $\left(\simeq 2 \mu \mathrm{mol} \cdot \mathrm{kg}^{-1} \cdot \mathrm{min}^{-1}\right)$ so any renal effect of insulin would be small. Furthermore, although the renal effect is attributable to arterial insulin, it cannot be considered to be an indirect effect of the hormone.

\section{Effects of a selective rise in the liver sinusoidal insulin level}

Our next aim was to assess the effect of liver sinusoidal insulin on glucose production. To this end we carried out a study in the overnight fasted conscious dog, but in this case we increased the portal vein (and thus liver sinusoidal) insulin concentration in the absence of any change in the arterial plasma insulin level [8]. Once again we carried out a pancreatic clamp using somatostatin and basal portal glucagon replacement, but in this case we used a combination of peripheral and portal insulin replacement. After a 40min control period the peripheral insulin infusion was turned off and the portal insulin infusion rate was increased by $1.2 \mathrm{pmol} \cdot \mathrm{kg}^{-1} \cdot \mathrm{min}^{-1}$. This resulted in an increase in portal vein insulin from 108 to 192 pmol/1 (Fig.3), although arterial insulin concentration did not change (54 to $60 \mathrm{pmol} / \mathrm{l})$. Euglycaemia (Fig. 3) was maintained by glucose infusion and plas-
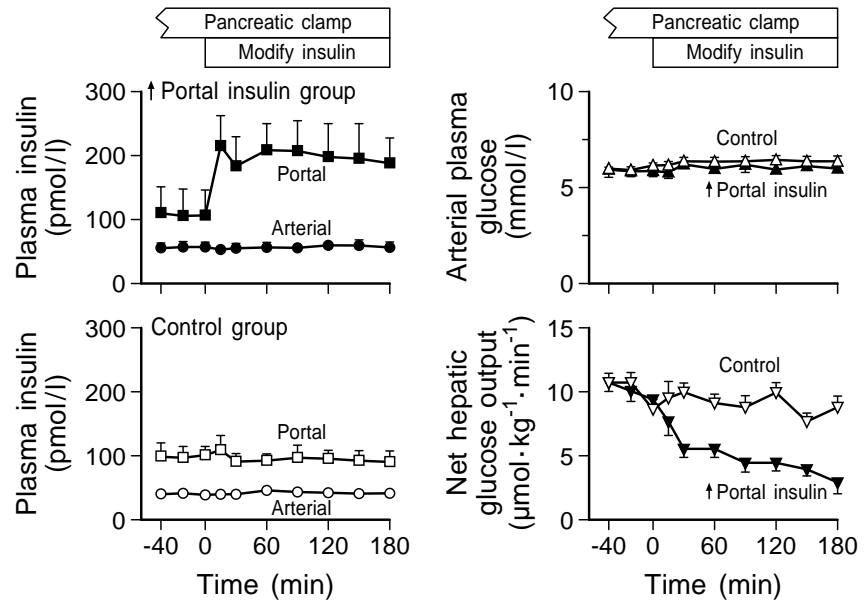

Fig. 3. The effect of a selective rise in portal vein insulin on net hepatic glucose, output in the conscious overnight fasted dog. Euglycaemia was maintained by glucose infusion and glucagon was kept basal. The data are redrawn from reference 8

ma glucagon was kept at its basal value $(\simeq 40 \mathrm{pg} /$ $\mathrm{ml})$. Net hepatic glucose output dropped from 10 to $6 \mu \mathrm{mol} \cdot \mathrm{kg}^{-1} \cdot \mathrm{min}^{-1}$ by $30 \mathrm{~min}$ and eventually fell to $3 \mu \mathrm{mol} \cdot \mathrm{kg}^{-1} \cdot \mathrm{min}^{-1}$. Tracer-determined glucose production showed a similar fall in glucose production (data not shown). This decline in net glucose output by the liver occurred in the complete absence of a rise in arterial insulin concentration, a fall in plasma glucagon or an increase in plasma glucose. It is thus clear that the liver responds quickly and sensitively to a selective rise in the liver sinusoidal insulin concentration. Furthermore, since there was no decrease in hepatic gluconeogenesis and no increase in net hepatic lactate output, it is evident that the change in glucose production reflected a decrease in glycogenolysis.

To determine if the route (hepatic artery vs portal vein) of insulin entry into the sinusoid makes any difference to insulin's direct action at the liver, we repeated the above study, giving the $1.2 \mathrm{pmol} \cdot \mathrm{kg}^{-1}$. $\mathrm{min}^{-1}$ increase in insulin infusion via the hepatic artery rather than the portal vein [20]. Again the plasma glucagon concentration was kept basal and euglycaemia was preserved. Net hepatic glucose output fell with a similar time course and to a similar extent as in the study described above. Thus the effect of increasing liver sinusoidal insulin is the same regardless of the route by which insulin enters the liver sinusoids.

\section{Effects of a selective deficiency in the liver sinusoidal insulin concentration}

To verify the importance of the direct action of insulin on the liver we next examined the effect of bringing about a selective deficiency of sinusoidal insulin on glucose production [21]. We again used the pan- 

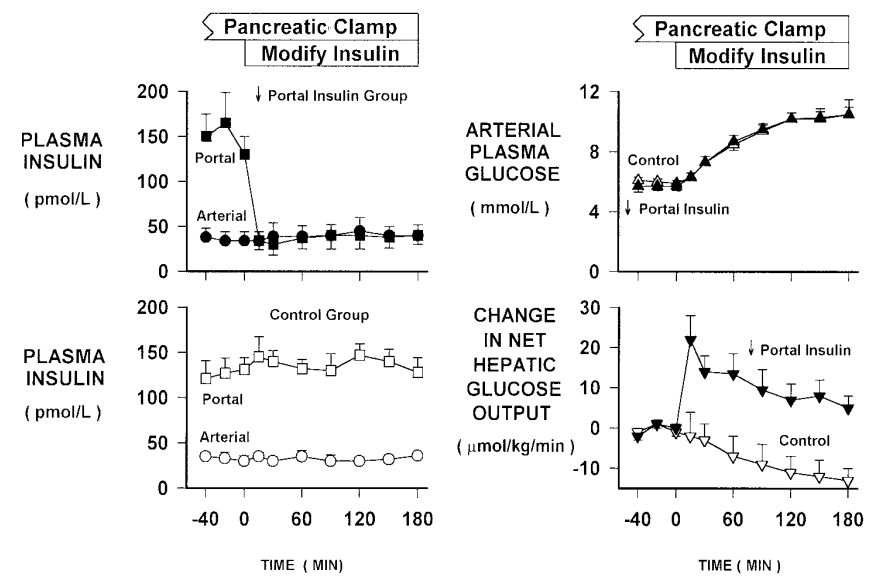

Fig. 4. The effect of a selective decrease in portal vein insulin on the arterial plasma glucose level hepatic glucose output in the conscious overnight fasted dog. Glucagon was kept basal. The data are redrawn from reference 21

creatic clamp technique in the overnight fasted conscious dog. In this case, after establishing the clamp, we stopped the portal insulin infusion and began a peripheral insulin infusion at half the portal infusion rate. Thereby the portal insulin concentration dropped from 150 to $30 \mathrm{pmol} / \mathrm{l}$, but the arterial insulin concentration remained unchanged (Fig.4). This selective decline in hepatic sinusoidal insulin $(\Delta 92 \mathrm{pmol} /$ 1) was associated with a rapid $(15 \mathrm{~min})$ increase in NHGO from 8 to $30 \mu \mathrm{mol} \cdot \mathrm{kg}^{-1} \cdot \mathrm{min}^{-1}(\Delta 22 \mu \mathrm{mol}$. $\mathrm{kg}^{-1} \cdot \min ^{-1}$; Fig. 4). Net glucose output by the liver declined thereafter. If one compares net hepatic glucose output in the insulin deficient group and equivalently hyperglycaemic control group, in which the portal insulin concentration was not altered, it is evident that the effect of liver sinusoidal insulin lack was almost the same $3 \mathrm{~h}$ after the induction of insulin deficiency as it was after 15 min of insulin lack. The tracer data also indicated a rapid and pronounced increase in glucose production in response to the decrease in liver sinusoidal insulin (data not shown). The magnitude of the change in tracer-determined glucose production was, however, only $60 \%$ of the increase in NHGO. This is explained by about $40 \%$ of the change in net hepatic glucose output being attributable to an inhibition, caused by insulin lack, of the hyperglycaemia-driven increase in hepatic glucose uptake which occurred in the control group. Gluconeogenesis by the liver did not increase during sinusoidal insulin deficiency and net hepatic lactate output did not decrease. The rise in net hepatic glucose output caused by the decline in liver sinusoidal insulin was therefore solely a reflection of an increase in glycogenolysis. This finding is critical to our thinking with regard to insulin's direct action on the liver. Clearly the binding of insulin to its hepatocyte receptors is responsible for its effect on hepatic glycogenolysis.

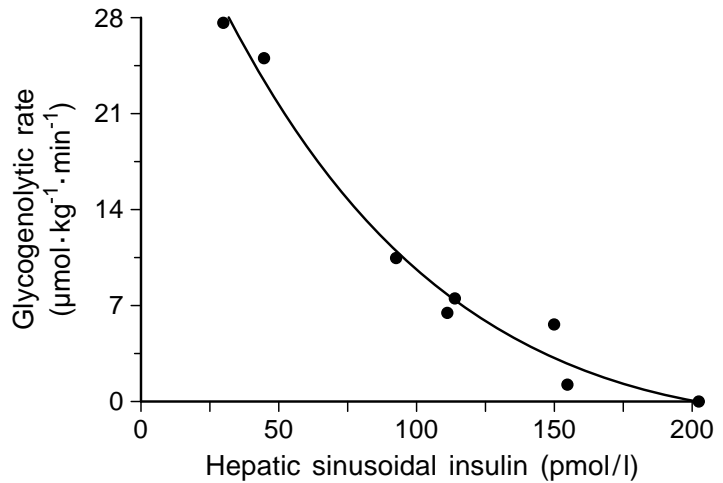

Fig. 5. The relation between the hepatic glycogenolytic rate and the hepatic sinusoidal insulin concentration in the conscious overnight fasted dog. Basal glucagon concentrations $(\simeq 40 \mathrm{pg} / \mathrm{ml})$ existed at all insulin concentrations. Euglycaemia existed at all but the two lowest insulin concentrations and in those cases the glycogenolytic rate represents the difference between the rate in the hypoinsulinaemic group and an equivalently hyperglycaemic control group at $30 \mathrm{~min}$ when only slight hypoglycemia $(\simeq 20 \mathrm{mg} / \mathrm{dl}$ ) was present. The data are contained in references $8,9,20,21,22$ and unpublished work of Edgerton et al.

Taken together, the data from the above studies regarding the effects of changes in liver sinusoidal insulin on hepatic glucose output show clearly that glucose production by the liver is rapidly and sensitively regulated by insulin's direct hepatic actions. Furthermore this effect is mediated exclusively by an inhibitory effect on glycogen breakdown. When one computes the sensitivity of hepatic glycogenolysis to the direct actions of insulin (Fig. 5), three things become evident. Firstly the half maximally effective level is below the insulin concentration which exists within the liver sinusoids $(\simeq 90-100 \mathrm{pmol} / \mathrm{l})$ after an overnight fast. Secondly a sinusoidal insulin concentration twice basal (180-200 pmol/l) would inhibit glycogenolysis by $80-90 \%$. This finding aids in the interpretation of data from earlier studies regarding the hepatic effects of increments in arterial (systemic) insulin. In general a better correlation was observed between the systemic insulin level and glucose production than the portal insulin level and glucose production. At the insulin levels used in those studies, however, the direct inhibitory effect of insulin on the liver was already substantial in the presence of the peripheral insulin infusion. The best correlation possible therefore would be with the systemic insulin concentration since the latter would decrease lipolysis and the net release of amino acids from muscle in a dosedependent manner. The earlier data of others $[2,5$, 6], although showing an indirect action of insulin on the liver, are therefore also consistent with a very sensitive response of the liver to the direct actions of the hormone. The third thing to be noted from Figure 5 relates to our earlier study of the inhibitory effect of a selective rise in systemic insulin. It was pointed out 

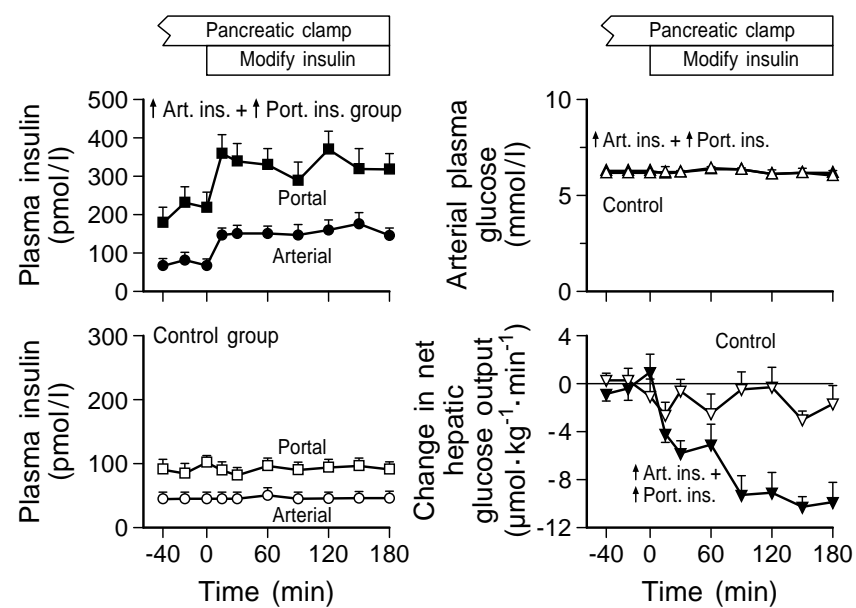

Fig. 6. The effects of equal increments in arterial and portal vein insulin on net hepatic glucose output in overnight fasted conscious dogs. Euglycaemia was maintained by glucose infusion and glucagon was kept basal. Data are redrawn from reference 22

previously that the rise in arterial insulin of $84 \mathrm{pmol} / \mathrm{l}$ which we brought about (NB the portal insulin level did not change) increased the hepatic sinusoidal insulin concentration by approximately $23 \mathrm{pmol} / \mathrm{l}$. We concluded that this must have inhibited glucose production by approximately $2 \mu \mathrm{mol} \cdot \mathrm{kg}^{-1} \cdot \mathrm{min}^{-1}$. The data in Figure 5 confirm that this would have been expected.

\section{Synergy between increments in arterial and liver sinusoidal insulin}

We next examined the synergy between equimolar increases in arterial and portal insulin concentrations. Again we used the overnight fasted conscious dog and the pancreatic clamp technique [22]. In this case equimolar increases in the arterial $(\Delta 102 \mathrm{pmol} / \mathrm{l})$ and portal vein $(\Delta 102 \mathrm{pmol} / \mathrm{l})$ insulin concentrations were brought about. The effects of the two changes were additive with regard to net hepatic glucose balance but not tracer-determined glucose production. The explanation for this is straightforward. Firstly, the rise in liver sinusoidal insulin was large enough to inhibit glycogen breakdown completely. An increase in net hepatic lactate output was observed, as expected, in the presence of a fall in NEFA. Since glycogenolysis was inhibited, however, the redirection of glucose carbon to lactate reflected increased uptake of glucose from the plasma. Estimation of hepatic glucose uptake using net hepatic ${ }^{3} \mathrm{H}$-glucose balance confirmed this interpretation $\left(\Delta 3.1 \mu \mathrm{mol} \cdot \mathrm{kg}^{-1}\right.$. $\left.\min ^{-1}\right)$. Since tracer-determined hepatic glucose uptake increased due to the rise in systemic insulin, the effects of the increments in arterial and portal insulin on net hepatic glucose output were additive and
NHGO fell from 9.8 to $0 \mu \mathrm{mol} \cdot \mathrm{kg}^{-1} \cdot \mathrm{min}^{-1}$. This was greater than the fall produced by either increment alone. Tracer-determined glucose appearance, on the other hand, which is blind to hepatic glucose uptake, was not appreciably greater when the arterial and portal increments in insulin were combined. In fact this would be expected because glucose production should decrease further when the increments are combined only by an amount equal to the sum of the decrease in gluconeogenic precursor flux to the liver (i.e. $\simeq 1 \mu \mathrm{mol} \cdot \mathrm{kg}^{-1} \cdot \mathrm{min}^{-1}$ ) and the decrease in renal glucose output $\left(\simeq 1 \mu \mathrm{mol} \cdot \mathrm{kg}^{-1} \cdot \mathrm{min}^{-1}\right)$ caused by the rise in arterial insulin. In fact tracer-determined glucose production was suppressed from 12.5 to $5.3 \mu \mathrm{mol} \cdot \mathrm{kg}^{-1} \cdot \mathrm{min}^{-1}$. Since glucose production fell by $2.0 \mu \mathrm{mol} \cdot \mathrm{kg}^{-1} \cdot \mathrm{min}^{-1}$ in the control study, the insulin-induced decline in tracer-determined glucose production was $5.2 \mu \mathrm{mol} \cdot \mathrm{kg}^{-1} \cdot \mathrm{min}^{-1}$, a value not significantly different from that seen with isolated increments in either arterial or hepatic sinusoidal insulin.

\section{Relative roles of the direct and indirect actions of insulin on the liver}

Having defined the ability of selective changes in systemic and liver sinusoidal insulin to alter hepatic glucose release and knowing the changes in arterial and sinusoidal insulin which occur in response to alterations in insulin secretion or subcutaneous insulin delivery, one can predict whether it is the sinusoidal or systemic insulin concentration which exerts the primary effect on the liver in each of these situations.

\section{Insulin secretion in a normal person}

In a normal animal doubling insulin secretion would raise the arterial insulin concentration from 42 to 84 $\mathrm{pmol} / \mathrm{l}$ and the portal insulin from 105 to $210 \mathrm{pmol} / \mathrm{l}$ (given that an average portal insulin concentration is 2.5 -fold that of the arterial). The liver sinusoidal insulin concentration would increase from 92 to $184 \mathrm{pmol} / 1$, a rise of $92 \mathrm{pmol} / \mathrm{l}$. Based on the data in Figure 5 a change in sinusoidal insulin of $92 \mathrm{pmol} / 1$ would reduce glycogenolysis by approximately $8.5 \mu \mathrm{mol}$. $\mathrm{kg}^{-1} \cdot \mathrm{min}^{-1}$. The rise in sinusoidal insulin resulting from the secretion of insulin into the portal vein ( $\simeq 83 \mathrm{pmol} / \mathrm{l}$ ) would by itself almost be enough to shut down glycogenolysis. Thus the recycling of insulin back to the liver (via the systemic circulation) would actually add in only a minor way to the decrease in glycogenolysis. The increase in arterial insulin would have only a limited ability to cause a diversion of glycogenolytic carbon to lactate (i. e. by reducing the NEFA concentration) because glycogenolysis would already be considerably reduced. The maximal 
effect could reduce glycogenolysis by an additional $1.5 \mu \mathrm{mol} \cdot \mathrm{kg}^{-1} \cdot \mathrm{min}^{-1}$. The rise in systemic insulin (42 pmol/l) would also inhibit gluconeogenic precursor flux to the liver. Since a rise of $84 \mathrm{pmol} / \mathrm{l}$ in arterial insulin reduced gluconeogenesis by $1 \mu \mathrm{mol} \cdot \mathrm{kg}^{-1}$. $\mathrm{min}^{-1}$, it can be assumed that a rise of $42 \mathrm{pmol} / \mathrm{l}$ would reduce it by $0.5 \mu \mathrm{mol} \cdot \mathrm{kg}^{-1} \cdot \mathrm{min}^{-1}$. A rise in arterial insulin of $42 \mathrm{pmol} / \mathrm{l}$ would be expected to have little, if any, effect on the plasma glucagon concentration, but it would be expected to reduce renal glucose production. Although the dose response characteristics are not clear, it is reasonable to assume that a rise of $42 \mathrm{pmol} / \mathrm{l}$ would at most produce a $50 \%$ fall in renal gluconeogenesis. If the latter averaged $2 \mu \mathrm{mol} \cdot \mathrm{kg}^{-1}$. $\mathrm{min}^{-1}$, this would amount to a fall of $1 \mu \mathrm{mol} \cdot \mathrm{kg}^{-1}$. $\mathrm{min}^{-1}$. The total effect of the rise in arterial insulin (remembering that liver sinusoidal insulin would reduce glycogenolysis by $8.5 \mu \mathrm{mol} \cdot \mathrm{kg}^{-1} \cdot \mathrm{min}^{-1}$ ) would thus be to reduce tracer-determined glucose production by an additional $3.0 \mu \mathrm{mol} \cdot \mathrm{kg}^{-1} \cdot \mathrm{min}^{-1}$ (the sum of the effects on increased glycolysis within the liver, the decrease in gluconeogenic precursor flux, and the inhibition of renal glucose output). As a result a total decrease in tracer-determined glucose production of $11.5 \mu \mathrm{mol} \cdot \mathrm{kg}^{-1} \cdot \mathrm{min}^{-1}$ would be expected, of which $8.5 \mu \mathrm{mol} \cdot \mathrm{kg}^{-1} \cdot \mathrm{min}^{-1}$ would be attributable to the rise in sinusoidal insulin (i.e. the direct effect of the hormone) and $3.0 \mu \mathrm{mol} \cdot \mathrm{kg}^{-1} \cdot \mathrm{min}^{-1}$ would be due to the rise in arterial insulin. Since the effect of the rise in arterial insulin on the kidneys $(1 \mu \mathrm{mol}$. $\mathrm{kg}^{-1} \cdot \mathrm{min}^{-1}$ ) should not be considered, the indirect effect of the hormone on the liver would cause a fall of $2 \mu \mathrm{mol} \cdot \mathrm{kg}^{-1} \cdot \mathrm{min}^{-1}$. Thus about $20 \%$ of the inhibition of hepatic glucose production resulting from a doubling of endogenous secretion would result from the indirect actions of the hormone on the liver and $80 \%$ from its direct hepatic effects. The decline in NEFA caused by the rise in the systemic insulin concentration might be expected to cause a small increase in the absolute rate of hepatic glucose uptake from plasma $\left(\simeq 0.5 \mu \mathrm{mol} \cdot \mathrm{kg}^{-1} \cdot \mathrm{min}^{-1}\right)$. This would reduce net hepatic glucose output by $0.5 \mu \mathrm{mol} \cdot \mathrm{kg}^{-1}$. $\min ^{-1}$ in addition to the $10.5 \mu \mathrm{mol} \cdot \mathrm{kg}^{-1} \cdot \mathrm{min}^{-1}$ resulting from the decrease in glycogenolysis $(10 \mu \mathrm{mol}$. $\mathrm{kg}^{-1} \cdot \min ^{-1} ; 8.5$ direct and 1.5 due to the decrease in NEFA) and the fall in gluconeogenesis $(0.5 \mu \mathrm{mol}$. $\left.\mathrm{kg}^{-1} \cdot \mathrm{min}^{-1}\right)$. As a result net hepatic glucose output would be expected to fall to a rate close to zero. Thus when the A-V difference technique is used to assess hepatic glucose production, the indirect effects attributable to a twofold basal insulin concentration would be an inhibition of glucose production by the liver of about $25 \%$.

If larger increments in insulin secretion are considered, the ever-increasing rise in the systemic insulin concentration would reduce renal glucose output and hepatic gluconeogenesis further. In this case, however, a complete inhibition of glycogenolysis would be expected to result from the additional increase in liver sinusoidal insulin concentration. This would prevent the indirect effect of insulin resulting from the fall in NEFA from redirecting G6P to lactate. If baseline glucose production was $15 \mu \mathrm{mol}$. $\mathrm{kg}^{-1} \cdot \mathrm{min}^{-1}$, and $10 \mu \mathrm{mol} \cdot \mathrm{kg}^{-1} \cdot \mathrm{min}^{-1}$ of that was due to glycogenolysis, inhibition of the latter by the sinusoidal insulin concentration could explain about $66 \%$ of the fall in tracer determined glucose production, assuming complete inhibition occurred. It therefore becomes apparent that regardless of the insulin secretion rate the maximal contribution possible due to the rise in arterial insulin after an overnight fast would be about $34 \%\left(5 \mu \mathrm{mol} \cdot \mathrm{kg}^{-1} \cdot \mathrm{min}^{-1}\right)$ of the fall in tracer-determined glucose production. Of that about $40 \%$ would be explained by a renal effect and the remainder $(60 \%)$ by the indirect effect of insulin on the liver. To the extent that the fall in NEFA would result in increased glucose entry into the liver, NHGO could become slightly negative. In the case of NHGO, therefore, the indirect effect of insulin could explain as much as $40 \%$ of the total response.

In the acute absence of insulin, liver glucose production can reach approximately $40 \mu \mathrm{mol} \cdot \mathrm{kg}^{-1}$. $\mathrm{min}^{-1}$. This is primarily the result of unrestrained glycogenolysis $(80 \%)$. Gluconeogenic precursor flux to the liver can change quickly following acute insulin deprivation, but any direct hepatic gluconeogenic effects of insulin lack require more than $3 \mathrm{~h}$ to be manifest [21]. As a result gluconeogenesis accounts for only about $20 \%$ of glucose production seen after acute insulin removal. As insulin secretion is restored it is primarily the direct effect of the hormone to repress glycogenolysis which decreases liver glucose output to normal. If a basal secretion rate were to be re-established the glycogenolytic rate would be reduced from 32 to $10 \mu \mathrm{mol} \cdot \mathrm{kg}^{-1} \cdot \mathrm{min}^{-1}$ and the gluconeogenic rate would be reduced from 8 to $5 \mu \mathrm{mol}$. $\mathrm{kg}^{-1} \cdot \mathrm{min}^{-1}$. Since the glycogenolytic change reflects the direct effect of insulin on the liver and the gluconeogenic change reflects the indirect effect of the hormone, it becomes obvious that slightly more than $85 \%$ of the restraining effect of basal insulin on glucose production can be attributed to a direct action of the hormone on the liver. If a fall in glucagon occurs in response to the restoration of basal insulin this would contribute to the fall in glycogenolysis and thus increase the indirect contribution of insulin somewhat. Since a lack of insulin within the liver sinusoid alone can increase glycogenolysis to $28 \mu \mathrm{mol}$. $\mathrm{kg}^{-1} \cdot \mathrm{min}^{-1}$ it is unlikely that a small rise in glucagon would increase it very much more. If the glucagon effect were approximately $4.0 \mu \mathrm{mol} \cdot \mathrm{kg}^{-1} \cdot \mathrm{min}^{-1}$, the indirect effects of insulin on the liver (including an alpha-cell effect) could still only explain $30 \%$ of the hormone's basal action. If the total effects of sinusoidal insulin (basal and any increase) are considered it becomes apparent that it is the direct action of the 
hormone on the liver which is predominant. In summary, in the case of endogenous insulin secretion the direct actions of the hormone are responsible for $60-85 \%$ of the hormone's inhibitory effect on the liver, with the remainder being due to its indirect actions on muscle, fat and the alpha cell. The exact per cent depends on the extent of insulin secretion and the method used to assess glucose production.

\section{Peripheral insulin delivery in a C-peptide negative person}

The situation in which insulin is delivered peripherally into C-peptide negative people with diabetes can now be considered. If insulin were to be infused into a peripheral vein at a rate equivalent to the basal insulin secretion rate assumed in the above example, the arterial insulin concentration would be $84 \mathrm{pmol} / 1$ and that of portal insulin would be approximately 71 $\mathrm{pmol} / \mathrm{l}$ since $15-20 \%$ of insulin is destroyed on first pass as blood traverses the gut [22]. The liver sinusoidal insulin level would be approximately $74 \mathrm{pmol} / \mathrm{l}$, somewhat below the $92 \mathrm{pmol} / \mathrm{l}$ seen in the presence of endogenous secretion. This would markedly restrain glycogen breakdown (relative to zero insulin) via a direct hepatic action and it would also reduce gluconeogenesis substantially. Given an expected $14 \mu \mathrm{mol} \cdot \mathrm{kg}^{-1} \cdot \mathrm{min}^{-1}$ reduction in glycogenolysis it is clear that the direct effect at the hormone would still be dominant.

Doubling insulin delivery would raise the arterial insulin concentration by $84 \mathrm{pmol} / \mathrm{l}$, that of portal insulin by $71 \mathrm{pmol} / \mathrm{l}$ and that of liver sinusoidal insulin by approximately $74 \mathrm{pmol} / \mathrm{l}$. The rise in the sinusoidal insulin concentration would directly reduce glycogenolysis by approximately $10 \mu \mathrm{mol} \cdot \mathrm{kg}^{-1} \cdot \mathrm{min}^{-1}$. In addition, the rise in arterial insulin would reduce glucagon secretion slightly, thereby further reducing glycogenolysis $\left(\simeq 2 \mu \mathrm{mol} \cdot \mathrm{kg}^{-1} \cdot \mathrm{min}^{-1}\right)$. An inhibition of glycogen breakdown equivalent to $12 \mu \mathrm{mol} \cdot \mathrm{kg}^{-1}$. $\min ^{-1}$ would thus be predicted (in the absence of altered hepatic insulin sensitivity). In addition, the rise in the systemic insulin to $168 \mathrm{pmol} / \mathrm{l}$ would reduce gluconeogenic precursor flow to the liver and, as a result, decrease hepatic gluconeogenesis by approximately $2.0 \mu \mathrm{mol} \cdot \mathrm{kg}^{-1} \cdot \mathrm{min}^{-1}$. The rise in arterial insulin might also be great enough to suppress renal gluconeogenesis completely $\left(2 \mu \mathrm{mol} \cdot \mathrm{kg}^{-1} \cdot \mathrm{min}^{-1}\right)$. Lastly, lipolysis would be inhibited resulting in a decline in NEFA which in turn would redirect G6P to lactate rather than glucose $\left(\simeq 2 \mu \mathrm{mol} \cdot \mathrm{kg}^{-1} \cdot \mathrm{min}^{-1}\right)$. Thus tracer-determined glucose production should decrease to a very low rate and net hepatic glucose output would be expected to approach zero. Given the above, approximately half of insulin's effect on overall glucose production would be due to the in- crease in the systemic insulin concentration. After taking into account the hormones' renal action it becomes clear that the indirect effect of insulin on the liver would account for $40 \%$ of its hepatic effect. In the presence of higher rates of peripheral insulin delivery, the per cent contribution of the indirect effects of insulin to inhibit glucose production would not be expected to change very much. Although a greater decrease in FFA and gluconeogenic precursor flux to the liver would occur, the further increase in liver sinusoidal insulin would shut down glycogenolysis completely via a direct mechanism. This would prevent the effect of insulin on the adipocyte (i.e. the decrease in NEFA) from affecting tracer-determined glucose production by the liver. To the extent that hepatic glucose uptake would increase due to the fall in NEFA a small amount of net hepatic glucose uptake might occur. In the case of net hepatic glucose output, therefore, the indirect effect of insulin could explain $50 \%$ of its action on the liver. If insulin resistance occurs selectively in peripheral tissues, then the overall decrease in glucose production would be reduced because of the decreased peripheral actions of insulin. The indirect effect of the hormone would then be reduced and the relative role of the direct actions of the hormone would be increased. In the case of peripheral insulin delivery to a C-peptide negative individual, therefore, it can be concluded that the importance of the direct and indirect actions of insulin on hepatic glucose production become equal as the rate of insulin infusion is increased.

\section{Peripheral insulin delivery in a normal person or one with Type II (non-insulin-dependent) diabetes mellitus}

If insulin is delivered peripherally into a normal person or one with Type II diabetes the situation becomes a little more complex. In this case an additional effect of the rise in the systemic insulin concentration becomes apparent, namely an inhibition of insulin secretion by the beta cell. As a result, a low dose insulin infusion can bring about a selective rise in the systemic insulin concentration with little or no change in the sinusoidal insulin concentration. This would lead to a response specifically due to the indirect effect of the hormone on the liver simply because there was little or no change in the hormone concentration to which the hepatocytes were exposed. This is how attention was drawn to the indirect action of insulin on the liver [2]. It also explains the recent data when insulin was infused at low doses into normal dogs in the absence of somatostatin [23]. It must be remembered, however, that the basal concentration of insulin that exists within the sinusoids is still exerting a powerful restraining effect on glycogenolysis even though the decrease in glucose production can be attributed to a rise in arterial insulin. Thus 
the overall effect of the hormone on the liver is still occurring, primarily by a direct action.

If our conclusions regarding insulin action are correct why did the early studies of others $[2,5,6]$ suggest an apparent predominant effect of systemic insulin levels on the liver? Firstly, none of those studies included time controls and the assumption was made that the basal glucose production would not change over the course of the study. In fact that is not the case, it would have declined about $10 \%$ over $3 \mathrm{~h}$. As a result the effect of insulin was modestly overestimated. Secondly, insulin concentrations in the portal vein were assumed and not measured and the glucagon concentrations were often not controlled, further complicating data interpretation. Thirdly, peripheral insulin infusion was associated with basal or above basal hepatic sinusoidal insulin concentrations and, given the sensitive manner in which the former inhibits glycogenolysis, a pronounced glycogenolytic inhibition resulting from the direct action of insulin on the liver was always present. The effect of portal insulin infusion was judged by the ability of the increase in the portal vein insulin concentration to further reduce glucose production over what was apparent during the peripheral infusion of insulin at half the portal rate. If the glycogenolytic inhibition was already substantial in the presence of peripheral insulin infusion it would be difficult for an increase in the sinusoidal insulin concentration to inhibit glucose production much further and the direct effect of the hormone would be underestimated. In a recent study [24] insulin was infused peripherally and glucagon was either under-replaced (groups 1 and 2) or the hepatic sinusoidal insulin concentration rose (groups 3 and 4). In the first two groups the deficiency of glucagon lowered the basal glycogenolytic rate, making it very difficult for a direct action of insulin on hepatic glucose output to be seen. In the latter two groups the rise in sinusoidal insulin undoubtedly reduced glycogenolysis to a relatively low rate. As a result delivery of insulin intraportally at twice the peripheral rate, (to increase the portal insulin concentration in the absence of a change in arterial insulin), increased the suppression of glucose production in groups 3 and 4 by only a small amount. This is not unexpected given the glycogenolytic inhibition already present in the presence of peripheral insulin infusion.

\section{Conclusion}

The liver sinusoidal insulin concentration is the primary determinant of the hepatic glucose production rate. Acutely lowering or raising the sinusoidal insulin concentration brings about rapid and sensitive changes in glycogenolysis. The indirect effect of a change in arterial (systemic) insulin on the liver results from an effect on the pancreatic alpha cell, the adipocyte and the muscle cell. At the alpha cell, insulin inhibits glucagon secretion, which in turn can alter hepatic glycogenolysis. In the adipocyte insulin inhibits lipolysis which reduces the supply of glycerol and NEFA reaching the liver. The former effect reduces gluconeogenesis while the latter causes a redirection of glycogen derived carbon to lactate rather than glucose. In the muscle cell insulin reduces the net output of gluconeogenic amino acids, thereby reducing hepatic gluconeogenesis. In addition a change in the arterial insulin concentration will alter renal glucose output, however the quantitative importance of this effect is likely to be small and it does not constitute part of the indirect effect of insulin on the liver.

In normal people changes in endogenous insulin secretion bring about their effect on liver glucose output primarily by a direct mechanism. The exact contribution will vary from 60 to $85 \%$ depending on the insulin secretion rate and the method used to assess liver glucose production. In a C-peptide negative diabetic person the direct effect of the hormone on the liver will dominate when insulin is delivered peripherally at a low rate but as the infusion rate increases the magnitude of the indirect and direct effects can become equal. In a normal person, or one with Type II diabetes, peripheral delivery of insulin at low rates decreases endogenous insulin secretion, in addition to its other actions. As a result a rise in arterial insulin will come about with little, if any, change in the liver sinusoidal insulin concentration. Under such a circumstance the indirect effects of the hormone will appear to dominate. It must be remembered, however, that even then the basal sinusoidal insulin concentration is exerting a powerful and important restraining effect on hepatic glucose production (in particular on glycogenolysis). As the delivery rate of insulin increases the liver sinusoidal insulin concentration will rise and the direct effect of the hormone on the liver will increase. At high infusion rates the direct effect will again be dominant.

\section{References}

1. Cherrington AD (1994) The acute regulation of hepatic glucose production. In: Pagliassotti M, Davis S, Cherrington $\mathrm{AD}$ (eds) The role of the liver in maintaining glucose homeostasis. R. G. Landes Company, Austin, pp 19-43

2. Prager R, Wallace P, Olefsky JM (1987) Direct and indirect effects of insulin to inhibit hepatic glucose output in obese subjects. Diabetes 36: 607-611

3. Cherrington AD, Wasserman DH, McGuinness OP (1994) Renal contribution to glucose production after a brief fast: fact or fancy. J Clin Invest 93: 2303 (Letter)

4. Cersosimo E, Judd ERL, Miles JM (1994) Insulin regulation of renal glucose metabolism in conscious dogs. J Clin Invest 93: 2584-2589

5. Ader M, Bergman RN (1990) Peripheral effects of insulin dominate suppression of fasting hyperglycemia. Am J Physiol 258: E1029-E1032 
6. Giacca A, Fisher S, Shi ZQ et al. (1992) Importance of peripheral insulin levels for insulin-induced suppression of glucose production in depancreatized dogs. J Clin Invest 90: 1769-1777

7. Lewis GF, Zinman B, Groenewoud Y, Vranic M, Giacca A (1996) Hepatic glucose production is regulated both by direct hepatic and extrahepatic effects of insulin in humans. Diabetes 45: 454-462

8. Sindelar DK, Balcom JH, Chu CA, Neal DW, Cherrington AD (1996) A comparison of the effects of selective increases in peripheral or portal insulin on hepatic glucose production in the conscious dog. Diabetes 45: 1594-1604

9. Sindelar DK, Chu CA, Rohlie M, Neal DW, Swift LL, Cherrington AD (1997) The role of fatty acids in mediating the effects of peripheral insulin on hepatic glucose production in the conscious dog. Diabetes 46: 187-196

10. Rebrin K, Steil GM, Getty L, Bergman RN (1995) Free fatty acid as a link in the regulation of hepatic glucose output by peripheral insulin. Diabetes 44: 1038-1045

11. Rebrin K, Steil GM, Mittleman SD, Bergman RN (1996) Causal linkage between insulin suppression of lipolysis and suppression of liver glucose output in dogs. J Clin Invest 93: 741-749

12. Boden G, Chen X, Ruiz J, White J, Rossetti L (1994) Mechanism of fatty acid-induced inhibition of glucose uptake. J Clin Invest 93: 2438-2446

13. Bevilacqua S, Bonadonna R, Buzzgoli G et al. (1987) Acute elevation of free fatty acid levels leads to hepatic insulin resistance in obese subjects. Metabolism 35: 502-506

14. Saloranta C, Taskinen M, Widen E, Harkonen M, Melander A, Groop L (1993) Metabolic consequences of sustained suppression of free fatty acids by acipimox in patients with NIDDM. Diabetes 42: 1559-1566

15. Lee KU, Lee HK, Koh CS, Min H (1988) Artificial induction of intravascular lipolysis by lipid-heparin infusion leads to insulin resistance in man. Diabetologia 31: 285-290
16. Myers SR, Diamond MP, Adkins-Marshall BA, Williams PE, Stinsen R, Cherrington, AD (1991) Effects of small changes in glucagon on glucose production during a euglycemic, hyperinsulinemic clamp. Metabolism 40: 66-71

17. Giacca A, Fisher SJ, McCall RH, Shi ZQ, Vranic M (1997) Direct and indirect effects of insulin in suppressing glucose production in depancreatized dogs: role of glucagon. Endocrinology 138: 999-1077

18. Lewis GF, Vranic M, Giacca A (1997) Glucagon enhances the direct suppressive effect of insulin on hepatic glucose production in humans. Am J Physiol 272: E371-E378

19. Dostou J, Meyer C, Gerich J (1998) Effects of physiologic hyperinsulinemia on human renal glucose metabolism and glutamine gluconeogenesis. Diabetes 47: A41 (Abstract)

20. Sindelar DK, Igawa K, Chu CA, Cherrington AD (198) The effect of sinusoidal insulin on hepatic glucose production is independent of route of entry into the liver. Diabetes 47: A281 (Abstract)

21. Sindelar DK, Chu CA, Venson P, Donahue P, Neal DW, Cherrington AD (1998) Basal hepatic glucose production is regulated by the portal vein insulin concentration. Diabetes 47: 523-529

22. Sindelar DK, Chu CA, Neal DW, Cherrington AD (1997) Interaction of equal increments in arterial and portal vein insulin on hepatic glucose production in the dog. Am J Physiol 273:E972-E980

23. McCall RH, Wiesenthal SR, Shi ZQ, Polonsky K, Giacca A (1998) Insulin acutely suppresses glucose production by both peripheral and hepatic effects in normal dogs. Am J Physiol 274: E346-E356

24. Mittleman SD, Fu Y-Y, Rebrin K, Steil G, Bergman RN (1997) Indirect effect of insulin to suppress endogenous glucose production is dominant, even with hyperglucagonemia. J Clin Invest 100: 3121-3130 